\title{
Urban legend or real fact: Coronary artery size varies with demographics
}

\author{
Mustafa Adem Tatlisu, ${ }^{1}$ Murat Sargin, ${ }^{2}$ Adnan Kaya, ${ }^{3}$ Ahmet Ilker Tekkesin, ${ }^{3}$ Zekeriya Nurkalem, ${ }^{4}$ \\ Serap Aykut Aka² \\ ${ }^{1}$ Department of Cardiology, Sivas Numune State Hospital, Sivas, Turkey \\ ${ }^{2}$ Department of Cardiovascular Surgery, Dr. Siyami Ersek Cardiovascular Surgery Research and Training Hospital, Istanbul, Turkey \\ ${ }^{3}$ Department of Cardiology, Dr. Siyami Ersek Cardiovascular Surgery Research and Training Hospital, Istanbul, Turkey \\ ${ }^{4}$ Department of Cardiology, Istanbul Medipol University Faculty of Medicine, Istanbul, Turkey
}

\begin{abstract}
OBJECTIVE: This study aimed to determine the relationship between the diameter of coronary artery stents and age, gender, diabetes mellitus (DM), left ventricular ejection fraction (LVEF), renal dysfunction, and the clinical presentation of myocardial ischemia in the cohort of patients with implanted stents in coronary arteries with severe stenotic lesions.

METHODS: This study included 2256 patients (mean age, 59.3 \pm 10.9 years; men, 62\%) who underwent percutaneous coronary intervention (PCI). The clinical status of the patients at presentation was subcategorized as follows: ST-segment elevation myocardial infarction, non-ST segment elevation myocardial infarction, unstable angina pectoris, and stable angina pectoris. The diameters, without any type or brand differentiation, were divided into two groups as follows: Group I, which included 2.5- and 2.75-mm-diameter stents, and Group II, which included $\geq 3$-mm-diameter stents.
\end{abstract}

RESULTS: The type of procedure, including primary PCI, early invasive strategy, and elective stenting, was not found to be a significant factor affecting the diameter of coronary artery stents. Univariate and multivariate analyses revealed a relationship between the diameter of coronary artery stents and age, gender, DM, and LVEF.

CONCLUSION: This study demonstrated that the diameter of coronary artery stents was independently associated with gender, age, a history of DM, and moderate-to-severe systolic left ventricular dysfunction.

Keywords: Coronary artery stent diameter; diabetes mellitus; effect; percutaneous coronary intervention.

G ender, age, and diabetes mellitus (DM) are some of the many claimed factors that affect the outcomes of coronary artery diseases related to mortality [1]. Besides these, the diameter of coronary artery is another parameter affecting the outcomes [2]. Several studies have shown that the luminal diameter after percutaneous revascularization is a strong predictor of restenosis $[3,4]$. Similarly, in coronary artery bypass surgery $(\mathrm{CABG})$, the target vessel size correlates with long-term graft patency $[5,6]$. Several angiographic and autopsy studies have ex- amined the possible relation between coronary arterial size and gender differences, and most of these studies have shown that women have smaller diameters of coronary artery $[7,8] . \mathrm{DM}$ and gender are other possible parameters that are related to coronary artery sizes.

However, a study of the diameters of coronary artery has several limitations, such as in cases of patients with angiographically normal coronary arteries or with an eccentric disease, diffuse atherosclerosis, and arterial compensatory enlargement or a study using nonstandard-

Received: July 05, 2017 Accepted: September 15, 2017 Online: January 11, 2018

Correspondence: Dr. Mustafa Adem TATLISU. Sivas Numune Devlet Hastanesi Kardiyoloji Anabilim Dali, Sivas, Turkey.

Tel: +905364439906 e-mail: ademtatlisu@gmail.com

(c) Copyright 2018 by Istanbul Provincial Directorate of Health - Available online at www.northclinist.com 
ized measurement techniques. In patients with coronary artery stents, the diameter of the implanted stents reflects the diameter of the coronary vessel at the lesion. Our study aimed to determine the relationship between the diameter of coronary artery stents and age, gender, DM, left ventricular ejection fraction (LVEF), renal dysfunction, and the clinical presentation of myocardial ischemia in a cohort of patients with implanted stents in coronary arteries with severe stenotic lesions.

\section{MATERIALS AND METHODS}

\section{Study Participants}

Our retrospective study included 2256 consecutive patients undergoing stent implantation to native coronary artery at Dr. Siyami Ersek Cardiovascular and Thoracic Surgery Training and Research Hospital, which serves as a tertiary catheterization laboratory of a high volume center [1194 primary percutaneous coronary intervention (pPCI) and 2032 elective PCI were performed by 25 interventional cardiologists in 2010] between January 1 and December 31,2013. Patients with native coronary stent implantation were included. A total of 46 patients were excluded because of the fact that transthoracic echocardiography was not performed in the first $24 \mathrm{~h}$ of admission. Demographic parameters were defined as age, gender, DM, LVEF, and creatinine levels. Creatinine levels and LVEF values were recorded before PCI. The clinical status of the patients at presentation was subcategorized as follows: ST-segment elevation myocardial infarction (STEMI), non-ST segment elevation myocardial infarction (NSTEMI), unstable angina pectoris (USAP), and stable angina pectoris (SAP). Stent diameters varied from 2.5 to $4 \mathrm{~mm}$. The diameter of stents, without any type or brand differentiation, was divided into two groups as follows: Group I, which included 2.5- and 2.75-mm-diameter stents, and Group II, which included $\geq 3$-mm-diameter stents. This study was approved by the Institutional Ethics Committee.

\section{Analysis of Patient Data}

Data on the clinical history of risk factors, such as age, gender, hypertension, DM, hyperlipidemia, and renal insufficiency was collected from the hospital's medical database. Echocardiographic and coronary angiographic findings were also obtained from the same database. A transthoracic echocardiogram was performed in $98 \%$ of patients in the first $24 \mathrm{~h}$ of admission to the coronary care unit, and LVEF was calculated using the Simpson method [9]. Patients with LVEF $\leq 40 \%$ were considered to have moderate-to-severe left ventricular systolic dysfunction [10]. Non-ionic low osmolality contrast media $(616 \mathrm{mosmol} / \mathrm{kg})$ were used in all patients. Patients with creatinine levels of $\geq 1.4 \mathrm{mg} / \mathrm{dL}$ were considered to have renal insufficiency $[11,12]$. After coronary angiography or pPCI, patients were admitted to the coronary care unit for follow-up. Drugs were administered during and after hospitalization as per the European Society of Cardiology Guidelines [13-15]. Blood values obtained from venous blood samples at hospital admission were recorded from medical reports. White blood cell counts, hemoglobin levels, and platelet counts were measured as part of the automated complete blood count using a Coulter LH 780 Hematology Analyzer (Beckman Coulter Ireland, Inc, Galway, Ireland). Biochemical measurements were performed using Siemens Healthcare Diagnostic Products kits and calibrators (Marburg, Germany). Creatine kinase isoenzyme-MB (CK$\mathrm{MB})$ levels were measured using an immune-inhibition method (Architect C 8000; Abbott Inc).

\section{Analysis of Patient Data}

All STEMI patients underwent pPCI within $1 \mathrm{~h}$ of admission, and all NSTEMI patients underwent PCI within $24 \mathrm{~h}$ of admission. All PCI procedures were performed using the standard femoral approach with a 6-Fr guiding catheter. Medication before pPCI included $600 \mathrm{mg}$ of clopidogrel and $300 \mathrm{mg}$ of chewable aspirin. Direct stenting was performed whenever possible, and balloon predilatation was performed in the remaining cases. The drug-eluting stent was used whenever possible. To achieve maximal dilation, an intracoronary injection of nitroglycerin $(100 \mu \mathrm{g})$ was administered in each coronary angiogram. All patients were treated with maintenance doses of clopidogrel (75 mg, once daily for 12 months) and aspirin (100 mg, indefinitely).

\section{Statistical Analysis}

Kolmogorov-Smirnov test was used for testing the normality. Continuous variables with normal distributions were expressed as mean $\pm \mathrm{SD}$ and compared using oneway analysis of variance. Continuous variables with skewed distributions were expressed as median (25th and 75th percentiles) and compared using KruskalWallis test. Categorical variables were expressed as number and percentages, and Pearson's chi-square or Fisher's exact tests were used to evaluate the differences. Differ- 
ences between the groups were analyzed using the logrank test. A forward Cox proportional regression model was used for multivariable analysis. In multivariable models, confounders in bivariate analysis as predictors of coronary stent diameter determinators were considered. A two-tailed p-value of $<0.05$ was considered statistically significant, and $95 \%$ CIs were presented for all odds ratios and hazard ratios. Analyses were performed using Statistical Package for Social Sciences software, version 20.0 (SPSS; IBM, Armonk, New York, USA).

\section{RESULTS}

A total of 2256 patients (mean age, $59.3 \pm 10.9$ years; men, $62 \%$ ) undergoing stent implantation to native coronary artery were included. Patients' baseline characteristics are listed in Table 1. Of the patients, 30.3\% had DM, $13.9 \%$ had renal dysfunction, and $71.8 \%$ had systolic left ventricular dysfunction, as shown in Table 1 . With respect to the clinical status of patients at presentation, the percentages of patients were as follows: STEMI, 56.2\%; NSTEMI and USAP, 24.2\%; and SAP, $19.7 \%$. Of the

TABLE 1. Baseline characteristics of patients

\begin{tabular}{lc} 
& $\mathrm{n}=2256(\%)$ \\
\hline Age & $59.3 \pm 10.9$ \\
Aged $\geq 65$ & $783(34.7)$ \\
Gender (male) & $1399(62)$ \\
Diabetes mellitus & $684(30.3)$ \\
Left ventricular ejection fraction ( $\leq 40 \%)$ & $1621(71.8)$ \\
Creatinine ( $\geq 1.4$ mg/dL) & $314(13.9)$ \\
Patients' status at admission & \\
$\quad$ ST-segment elevation myocardial infarction & $1267(56.2)$ \\
$\quad$ Non-ST segment elevation myocardial & $545(24.2)$ \\
$\quad$ infarction, Unstable angina pectoris & \\
$\quad$ Stable angina pectoris & $444(19.7)$ \\
Coronary stent diameters & \\
$\quad<3$ mm & $440(19.5)$ \\
$\quad \geq 3$ mm & $1816(80.5)$ \\
Coronary arteries & \\
$\quad$ Left anterior descending artery & $1270(56.3)$ \\
Diagonal artery & $194(8.6)$ \\
Circumflex artery & $55(2.4)$ \\
Right coronary artery & $737(32.7)$ \\
\hline
\end{tabular}

Continuous variables are presented as median and 25-75 percentiles; nominal variables presented as frequency (\%). Mann-Whitney-U test was used for continuous variables. Pearson-Chi-Square test was used for nominal variables. patients, $19.5 \%$ received coronary artery stents of $<3$ mm diameter.

Table 2 lists unadjusted and adjusted hierarchical logistic regression analysis for diameters of coronary artery stents. The type of the procedure, including pPCI, early invasive strategy, and elective stenting, was not found to be a significant factor affecting the diameter of coronary artery stents (Table 2). Although renal dysfunction was found to be a factor affecting the diameter of coronary artery stents in univariate analysis, this significant relationship did not persist after adjustment for all confounders. The significant relationship was found between the diameter of coronary artery stents and age, gender, DM, and LVEF in univariate analysis $(\mathrm{p}<0.001)$, which persisted even after adjusting for all confounders (Table 2).

\section{DISCUSSION}

Gender, age, chronic renal failure, congestive heart failure, and DM are significant predictors of clinical outcomes after PCI. Patients with smaller target vessels have a significantly higher rate of restenosis; however, this does not imply that coronary stents should not be placed into smaller vessels. A meta-analysis of 11 randomized trials has shown that stenting is superior to balloon angioplasty in small coronary vessels [16]. Although several studies have been conducted on vessel sizes with angiographically normal coronary arteries [17-19], those on vessel sizes with atherosclerotic coronary arteries are rare.

In multivariate analysis, age, a history of DM, systolic left ventricular dysfunction, and female gender were found to be associated with coronary vessel size. Our findings support those of previous studies on vessel sizes. Several studies have focused only on gender [17, 18]; therefore, we investigated the relationship between coronary vessel sizes and age, DM, LVEF, renal dysfunction, and the clinical presentation of myocardial ischemia. Before coronary intervention, interventional cardiologists have several preconceptions regarding elderly patients [20] and/or patients with DM that they have considerably smaller coronary vessels than other patients. Our findings were consistent with those observed in our practical experience. Because we received only coronary vessels that were intervened, we could not receive those that could not be intervened. As known by several interventional cardiologists, vessels that cannot be intervened are comparatively smaller than those that are intervened, particularly in patients with DM. Nevertheless, older age, DM, LVEF, and female gender were found to be as- 
TABLE 2. Univariate predictors and multivariate hierarchical logistic regression analysis for coronary artery stent diameters. All clinically relevant parameters were included in the model

\begin{tabular}{lcccc} 
Univariate analysis & $\begin{array}{c}\text { Stent size }<3 \mathrm{~mm} \\
\mathrm{n}(\%)\end{array}$ & $\begin{array}{c}\text { Stent size } \geq 3 \mathrm{~mm} \\
\mathrm{n}(\%)\end{array}$ & $\mathrm{p}$ & OR (95\% CI) \\
\hline Age $(<65$ years) & $173(11.7)$ & $1300(88.3)$ & $<0.001$ & $3.891(3.134-4.830)$ \\
Gender (male) & $164(11.7)$ & $1235(88.3)$ & $<0.001$ & $3.577(2.880-4.444)$ \\
Diabetes mellitus & $192(28.1)$ & $492(71.9)$ & $<0.001$ & $0.480(0.387-0.595)$ \\
LVEF $(\leq 40 \%)$ & $358(22.2)$ & $1263(77.9)$ & $<0.001$ & $0.523(0.403-0.678)$ \\
Creatinine $(\geq 1.4 \mathrm{mg} / \mathrm{dL})$ & $47(15.0)$ & $267(85.0)$ & $<0.05$ & $1.442(1.038-2.005)$ \\
Type of the procedure & & & & \\
$\quad$ Primary PCI & $276(21.8)$ & $981(78.2)$ & $>0.05$ & $0.813(0.618-1.069)$ \\
$\quad$ Early invasive strategy & $82(15.0)$ & $463(85.0)$ & $>0.05$ & $1.278(0.914-1.788)$ \\
$\quad$ Elective stenting & $82(18.5)$ & $362(81.5)$ & $>0.05$ & $1.056(0.729-1.365)$ \\
\hline Multivariate analysis & Stent size $<3 \mathrm{~mm}$ & Stent size $\geq 3 \mathrm{~mm}$ & $\mathrm{p}$ & OR (95\% CI) \\
& $\mathrm{n}(\%)$ & $\mathrm{n}(\%)$ & & \\
\hline Age $(<65$ years) & $173(11.7)$ & $1300(88.3)$ & $<0.001$ & $4.791(3.761-6.102)$ \\
Gender (male) & $164(11.7)$ & $1235(88.3)$ & $<0.001$ & $2.267(1.762-2.914)$ \\
Diabetes mellitus & $192(28.1)$ & $492(71.9)$ & $<0.001$ & $0.569(0.444-0.730)$ \\
LVEF $(\leq 40 \%)$ & $358(22.2)$ & $1263(77.9)$ & $<0.001$ & $0.416(0.307-0.562)$ \\
Creatinine $(\geq 1.4 \mathrm{mg} / \mathrm{dL})$ & $47(15.0)$ & $267(85.0)$ & 0.08 & $1.231(0.915-1.742)$ \\
\hline
\end{tabular}

Only parameters that reached statistical significance at univariate analysis were given in the rows below. OR: Odds ratio; CI: confidence interval; LVEF: left ventricular ejection fraction; PCI: percutaneous coronary intervention.

sociated with smaller final stent sizes in our study. Furthermore, we could not find the association between final stent size and the presentation of ischemic heart diseases such as STEMI, NSTEMI, USAP, and SAP. Although patients with STEMI have increased catecholamine and inflammatory cells that may cause coronary spasm during the procedure, we did not find any relationship between STEMI and diameters of coronary stents, which might be because of the routine intracoronary injection of nitroglycerin before stent implantation. Because of intracoronary nitrates, the implanted stent size in patients with STEMI reflects the appropriate final stent size.

\section{Limitations}

There are some limitations to our study. Forty-six patients were excluded because transthoracic echocardiography was not performed in the first $24 \mathrm{~h}$ of admission. Our study population was limited to patients undergoing PCI. Therefore, our results cannot be generalized to patients with normal coronary vessels. The study was conducted in a single tertiary referral heart center. Because high-risk patients are referred for PCI to our heart center, it may have affected our results. As shown in Table $1,71.8 \%$ of the patients had moderate-to-severe systolic left ventricular dysfunction. Another limitation of the study is its retrospective design because of which we could not calculate the body mass index that may affect the diameter of coronary artery vessels and also could not utilize more accurate diagnostic tools, such as intravascular ultrasound and optical coherence tomography, to measure the diameter of vessels.

\section{CONCLUSION}

This study demonstrated that diameters of coronary artery stents were independently associated with gender, age, a history of DM, and moderate-to-severe systolic left ventricular dysfunction.

Ethics Committee Approval: This study was approved by the Institutional Ethics Committee.

Conflict of Interest: No conflict of interest was declared by the authors.

Financial Disclosure: The authors declared that this study has received no financial support. 
Authorship contributions: Concept - M.A.T.; Design - M.A.T.; Supervision - O.K.; Materials - A.K., M.K.; Data collection \&/or processing - A.K., M.K.; Analysis and/or interpretation - M.A.T.; Writing - M.A.T.; Critical review - O.K.

\section{REFERENCES}

1. Pilote L, Dasgupta K, Guru V, Humphries KH, McGrath J, Norris C, et al. A comprehensive view of sex-specific issues related to cardiovascular disease. CMAJ 2007;176:S1-44. [CrossRef]

2. Hoffmann R, Mintz GS. Coronary in-stent restenosis - predictors, treatment and prevention. Eur Heart J 2000;21:1739-49. [CrossRef]

3. Tsai ML, Chen CC, Chen DY, Yang CH, Hsieh MJ, Lee CH, et al. Review: The outcomes of different vessel diameter in patients receiving coronary artery stenting. Int J Cardiol 2016;224:317-22. [CrossRef]

4. Saucedo JF, Popma JJ, Kennard ED, Talley JD, Lansky A, Leon MB, et al. Relation of coronary artery size to one-year clinical events after new device angioplasty of native coronary arteries (a New Approach to Coronary Intervention [NACI] Registry Report). Am J Cardiol 2000;85:166-71. [CrossRef]

5. O'Connor NJ, Morton JR, Birkmeyer JD, Olmstead EM, O'Connor GT. Effect of coronary artery diameter in patients undergoing coronary bypass surgery. Northern New England Cardiovascular Disease Study Group. Circulation 1996;93:652-5. [CrossRef]

6. Mickleborough LL, Carson S, Ivanov J. Gender differences in quality of distal vessels: effect on results of coronary artery bypass grafting. J Thorac Cardiovasc Surg 2003;126:950-8. [CrossRef]

7. Yang F, Minutello RM, Bhagan S, Sharma A, Wong SC. The impact of gender on vessel size in patients with angiographically normal coronary arteries. J Interv Cardiol 2006;19:340-4. [CrossRef]

8. Dickerson JA, Nagaraja HN, Raman SV. Gender-related differences in coronary artery dimensions: a volumetric analysis. Clin Cardiol 2010;33:E44-9. [CrossRef]

9. Schiller NB, Shah PM, Crawford M, DeMaria A, Devereux R, Feigenbaum $\mathrm{H}$, et al. Recommendations for quantitation of the left ventricle by two-dimensional echocardiography. American Society of Echocardiography Committee on Standards, Subcommittee on Quantitation of Two-Dimensional Echocardiograms. J Am Soc Echocardiogr 1989;2:358-67. [CrossRef]

10. McMurray JJ, Adamopoulos S, Anker SD, Auricchio A, Böhm M, Dickstein $\mathrm{K}$, et al. ESC Guidelines for the diagnosis and treatment of acute and chronic heart failure 2012: The Task Force for the Diagnosis and Treatment of Acute and Chronic Heart Failure 2012 of the European
Society of Cardiology. Developed in collaboration with the Heart Failure Association (HFA) of the ESC. Eur Heart J 2012;33:1787-847.

11. Mann JF, Gerstein HC, Pogue J, Bosch J, Yusuf S. Renal insufficiency as a predictor of cardiovascular outcomes and the impact of ramipril: the HOPE randomized trial. Ann Intern Med 2001;134:629-36. [CrossRef]

12. Shlipak MG, Simon JA, Grady D, Lin F, Wenger NK, Furberg CD; Heart and Estrogen/progestin Replacement Study (HERS) Investigators. Renal insufficiency and cardiovascular events in postmenopausal women with coronary heart disease. J Am Coll Cardiol 2001;38:705-11.

13. Task Force on the management of ST-segment elevation acute myocardial infarction of the European Society of Cardiology (ESC), Steg PG, James SK, Atar D, Badano LP, Blömstrom-Lundqvist C, Borger $\mathrm{MA}$, et al. ESC Guidelines for the management of acute myocardial infarction in patients presenting with ST-segment elevation. Eur Heart J 2012;33:2569-619.

14. Hamm CW, Bassand JP, Agewall S, Bax J, Boersma E, Bueno H, et al. ESC Guidelines for the management of acute coronary syndromes in patients presenting without persistent ST-segment elevation: The Task Force for the management of acute coronary syndromes (ACS) in patients presenting without persistent ST-segment elevation of the European Society of Cardiology (ESC). Eur Heart J 2011;32:2999-3054.

15. Fox K, Garcia MA, Ardissino D, Buszman P, Camici PG, Crea F, et al Guidelines on the management of stable angina pectoris: executive summary: The Task Force on the Management of Stable Angina Pectoris of the European Society of Cardiology. Eur Heart J 2006;27:1341-81.

16. Moreno R, Fernández C, Alfonso F, Hernández R, Pérez-Vizcayno MJ, Escaned J, et al. Coronary stenting versus balloon angioplasty in small vessels: a meta-analysis from 11 randomized studies. J Am Coll Cardiol 2004;43:1964-72. [CrossRef]

17. Kucher N, Lipp E, Schwerzmann M, Zimmerli M, Allemann Y, Seiler C. Gender differences in coronary artery size per $100 \mathrm{~g}$ of left ventricular mass in a population without cardiac disease. Swiss Med Wkly 2001;131:610-5.

18. Sheifer SE, Canos MR, Weinfurt KP, Arora UK, Mendelsohn FO, Gersh BJ, et al. Sex differences in coronary artery size assessed by intravascular ultrasound. Am Heart J 2000;139:649-53. [CrossRef]

19. Zindrou D, Taylor KM, Bagger JP. Coronary artery size and disease in UK South Asian and Caucasian men. Eur J Cardiothorac Surg 2006;29:492-5. [CrossRef]

20. Russ MA, Wackerl C, Zeymer U, Hochadel M, Kerber S, Zahn R, et al. Gender based differences in drug eluting stent implantation - data from the German ALKK registry suggest underuse of DES in elderly women. BMC Cardiovasc Disord 2017;17:68. [CrossRef] 